\title{
The Development of Creativity of Students in Higher Education: Innovative Pedagogical Management
}

\author{
Nadzeya Nizhneva-Ksenofontova ${ }^{1}$ Natallia Nizhneva, ${ }^{1, *}$ \\ ${ }^{1}$ Belarusian State University, Minsk, Belarus \\ *Corresponding author. Email: nizhneva_nn@mail.ru
}

\begin{abstract}
The article is devoted to innovative pedagogical management as a very important factor of developing creativity of students in higher education. Main functions of management and innovative pedagogical management are analyzed. Special attention is paid to the goal, main tasks, features, effective model of innovative pedagogical management and important conditions for its implementation. Two main types of innovative management in education (strategic and functional) are described. The conditions for effective implementation of innovative pedagogical management for developing students' creativity are analyzed. The essence of creativity and the creative situation (as one of effective means of developing students' creativity) are in the focus of attention.
\end{abstract}

Keywords: Management, Innovative pedagogical management, Conditions for implementation of innovative pedagogical management, Creativity, Development of creativity, Creative situation.

\section{INTRODUCTION}

The problem of qualified specialist training and the development of optimal ways to include $\mathrm{him} / \mathrm{her}$ in professional activities is almost an eternal problem of the education system [1-4].

One of the most important issues of modern pedagogy is the problem of determining the optimal pedagogical conditions that promote creative development and self-development of the individual, initiative, the ability to creative professional activity, constructive, non-standard thinking and behavior, as well as awareness and development of their experience.

Under these conditions, management acquires great importance to realize the purposes in view.

\section{INNOVATIVE PEDAGOGICAL MANAGEMENT}

\subsection{The Art of Good Management: Main Functions}

First of all it is necessary to discuss the main functions of management [5]. Henry Fayol considers them to be universal and very important for performing by every manager.
According to Henry Fayol, the five functions of management are:

- 1. Planning - drawing up plans of actions that combine unity, continuity, flexibility and precision, type and significance of work and future trends. Creating a plan of action is the most difficult of the five tasks and requires active participation of the entire organization. Planning must be coordinated on different levels and with different time horizons.

- 2. Organizing - providing capital, personnel and raw materials for the day-today running of business, and building a structure to match the work. Organizational structure depends entirely on the number of employees. An increase in the number of functions expands the organization horizontally and promotes additional layers of supervision.

- 3. Commanding - optimizing return from all employees in the interest of the entire enterprise. Successful managers have personal integrity, communicate clearly and base their judgments on regular audits. Their thorough knowledge of personnel creates unity, energy, initiative and loyalty and eliminates incompetence. 
- 4. Coordinating - unifying and harmonizing activities and efforts to maintain balance between the activities of the organization. Fayol recommended weekly conferences for department heads to solve problems of common interest.

- 5. Controlling - identifying weaknesses and errors by controlling feedback, and conforming activities to plans, policies and instructions. Fayol's management process went further than Taylor's basic hierarchical model by allowing command functions to operate efficiently and effectively through co-ordination and control methods [6].

Everard and Morris [7] believe that the manager's missions should be:

- to utilize and integrate resources economically in the pursuit of organizational goals;

- to facilitate beneficial change;

- to maintain and develop resources.

\subsection{The Key to Success: Innovative Pedagogical Management}

Pedagogical management is of particular importance. It is interconnected with the creative activities of its participants. There are different approaches to determine the content of pedagogical management. In particular, pedagogical management is understood as the theory, methodology and technology of effective management of the educational process [8].

It is also indicated that innovative pedagogical management, as a process, in the cycle of its development involves:

- goal-setting,

- modeling a new idea,

- implementation of the conceived idea,

- correction and reflection,

- introduction and dissemination of the idea,

- decline.

It is noted that in conditions of innovative pedagogical management, the process of personal self-determination of both students and teachers is activated, which affects the nature of people's relationships [8].

Innovative management in an educational institution is also considered as "a set of scientifically based principles, forms, methods, techniques and tools for managing innovations in the field of their creation, development in the educational process in order to improve the quality of education and promote it to the market in order to make a profit" [9].

The main goal of innovative management is revealed as ensuring functioning and development of an educational institution on the basis of effective organization of innovative processes and high competitiveness of innovative products [9].

Innovative management involves solving the following tasks:

- development and implementation of a unified innovation policy in the university;

- defining the strategic directions of innovation activities and setting goals in each of them and choosing the optimal innovation development strategy for each direction;

- organization of innovation activities and motivation of participants in innovation activities;

- financial and material support of innovation projects;

- training personnel for innovation activities and the formation of target teams, groups for the implementation of innovative projects;

- regular assessment of the results of innovation activities and others [9].

In the process of implementing innovative pedagogical management, it is necessary to take into account its features:

- the ability to achieve significantly higher results;

- $\quad$ positive attitude to the new;

- novelty of the work performed;

- ability to realize personal needs of the highest level: self-expression, selfactualization, high creative results;

- the need for continuous improvement of professional competence and the possibility of expanding the system of requirements for the personal qualities of participants in the innovation process, and others [10].

Of particular importance is the choice of the optimal model of innovative pedagogical 
management, designed in accordance with the following criteria:

- the integrity of the program content and the relationship of its structural parts or blocks;

- necessary recommendations for the program;

- $\quad$ expert opinion and others [10].

The control of results becomes especially relevant in innovative pedagogical management, which involves:

- expert and analytical assessment of the achieved results;

- evaluation of specific results;

- evaluation of the results of innovation management in accordance with the objectives and the relevant conclusions on the regulation of control actions;

- establishment of direct and feedback communication for informing and others [10].

For the successful development of an educational institution, it is necessary to take into account important conditions for the implementation of innovative pedagogical management:

- the need for innovation;

- regulatory and legal support;

- personnel, information and analytical support;

- innovative culture of participants in the educational space [10].

Besides, there are two main types of innovative management in education: strategic and functional.

Strategic innovative management is considered as a system that includes five elements: the ability to identify problems; the ability to formulate goals; the ability to develop basic strategies; the ability to implement strategies; the ability to make adjustments to the strategy [10].

Functional innovative management in education is aimed at forecasting the creation of new systems of education and training, effective technologies; analysis of factors of the effectiveness of innovation activities; development, implementation and development of innovations, and others [11].

In modern conditions, innovative pedagogical management is an important factor in the formation of students' creativity in the education system. It is the creation of conditions that promotes the manifestation of students' creativity, which is also associated with the development of professional competencies in their hierarchy that modern university education is focused on.

Against the background of the processes of changing educational paradigms, the introduction of new pedagogical technologies in training, taking into account the social order of training specialists with a pronounced creative potential and being capable of self-realization in the profession and society become even more urgent [12].

\subsection{Conditions for the Development of Students' Creativity}

The effectiveness of implementation of innovative pedagogical management to develop students' creativity depends on a number of conditions.

The first condition is the use of optimal innovative educational technologies and innovations. At the same time, innovative educational technology is considered as a complex that includes three interrelated components:

- 1. Modern content, which should be presented in the form of multimedia educational materials and aimed at developing competencies that are adequate to modern practice.

- 2. Modern teaching methods that are based on the interaction of students and their involvement in the educational process and aimed at the formation of the necessary competencies.

- 3. Modern training infrastructure, including information, technological, organizational and communication components that provide effective usage of the advantages of distance learning [13].

In particular, innovative management technologies in the modern educational process can be implemented through the creation of educational, scientific and innovative complexes, which involve the organization of a single educational, scientific and organizational space [14].

Modern education should be based on innovations aimed at developing the creative potential of students, in particular, such as: the theory of solving inventive problems [15]; the system of continuous creative education [16]; the system of open-type tasks [17]. 
The second important condition is the need to take into account the specifics of the modern educational paradigm, the center of which is not a student who learns ready-made knowledge, but a person who learns the truth. At the same time, cooperation, co-creation, dialogue, and exchange of views become the main principles on which interactions and relationships of participants in the pedagogical process are built.

Under current conditions, the differences between the traditional educational paradigm and the innovative one are clearly visible.

In particular, these differences are observed in: methods of education; content of education (a certain amount of known knowledge, skills and creativity); criteria of effectiveness (formal indicators of academic performance and concrete results of practice); forms of organization (individual-group and collective-individual); pedagogical function (impact on the student as an object and activation of students); trends of dynamics (stability and continuous updating) [18].

The third important condition is the creation of the basis for the development of creativity.

\section{THE DEVELOPMENT OF CREATIVITY OF STUDENTS IN HIGHER EDUCATION}

Innovative pedagogical management is considered to be a very important factor of developing creativity of students.

To achieve this aim, it is necessary to meet several requirements.

\subsection{Not to Lock Creativity: Creative Approach}

First of all, the realization of creative approach assumes a particular significance. It is attracting increasing interest with good reason [19]-[23].

Creative thinking, creativity, creative field, creative sphere, mechanisms of creativity development, creative persons and motivated creative persons are analyzed. Tasks, conditions and means of creative development of a creative personality in the academic process, peculiarities, characteristics, structure, and levels of creative cognitive activity are described. All these problems acquire great importance because creativity is considered to be the basis of innovative education.

\subsection{Barriers to Creativity and Not Only...}

The development of creativity is not possible without teachers possessing deep knowledge about the essence of creativity that is studied across many disciplines [24]-[26] and is defined as:

- a special type of sensitivity to the problems connected with lack of knowledge, identification of difficulties, processes of setting up a hypothesis;

- the creative process of producing something new;

- "the act of turning new and imaginative ideas into reality. Creativity involves two processes: thinking, then producing" [27];

- integrated quality of a person.

Michael Mumford suggested: "Over the course of the last decade, however, we seem to have reached a general agreement that creativity involves the production of novel, useful products" [28].

Rollo May claims: "Creativity is the process of bringing something new into being...creativity requires passion and commitment. Out of the creative act are born symbols and myths. It brings to our awareness what was previously hidden and points to new life. The experience is one of heightened consciousness-ecstasy" [29].

Todd I. Lubart and Robert J. Sternberg describe creativity in the following way:

"A product is creative when it is (a) novel and (b) appropriate. A novel product is original not predictable. The bigger the concept, and the more the product stimulate further work and ideas, the more the product is creative" [30].

In this connection, highly knowledgeable teachers should be well familiar with six guiding ideas to grasp the essence of creativity. Albert, as quoted in Feldhusen and Goh, states that they are: creativity is expressed through decisions, not products; knowledge of self and of one's world is the medium of creative behavior; creative behavior is highly intentional; creativeness and personal identity are emergent; creative behavior and creativeness and personal identity are mutually dependent; creative behavior engages individuals at the personal level of their identities and abilities [31].

In addition, it is crucially important to take into account the stages of the creative process that according to Leonard and Swap includes: "1) preparation, 2) innovation opportunity, 3) 
divergence or the generation of options, 4) incubation, and 5) convergences or the selection of options" [32]. Here we combine divergence, convergence and innovation.

Besides, teachers should possess knowledge about four behaviors that prepare the mind for creativity. According to Smith and Paradice they are: 1) learn something new every day, 2) seek out constructive criticism, 3) incubate, or leave a problem alone for a while to allow the brain to work on it, and 4) put knowledge to work [33].

And of course, it is impossible to develop students' creativity without taking into consideration barriers to creativity. Thomas describes them in his list that is based on the work of Alexander Hiam, and includes nine barriers: failures to ask questions; to record ideas; to revisit ideas; to express ideas; to think in new ways; to wish for more; to try being creative; to keep trying; to tolerate creative behavior [34].

\subsection{Creativity Cannot Be Used Up: Creative Situations}

To develop creativity in conditions of innovative pedagogical management it is important to use efficient methods and techniques.

In the process of the research it was found out that the learning/teaching process is effective when it includes complete blocks of creative situations for the implementation of different types of creative activities. A conceptual model of learning/teaching has been created on the basis of new fundamental principles such as: the principle of professionallyoriented polytomy, the principle of quaternary, the principle of brain balancing, the erothematic principle, the principle of creative participation, the principle of synergy.

The results of the research demonstrate that the most distinctive feature of creative situations is their ability to encourage and develop creative activities of students that do not limit their intellectual activity. In general, a creative situation may be defined as a complex of external conditions and diverse forms of individual and teamwork that spur students to intellectual creative activity, promoting the development of creative motivation.

Findings prove that main parameters of creative situations are cognitive value, purposefulness, context, motives and aims, exchange of new information, encouragement of intellectual activity of students.
Key principles of developing creative situations are described in the following way: systematic and founded complication, encouragement and development of creative, cognitive links of intellectual activity of students, and their intellectual creative abilities.

It is determined that creative situations may be classified according to:

- the means of solving problems or contradictions;

- character of cognitive activity performed;

- level of difficulty of contradictions.

Types of contradictions:

- contradictions of informative and cognitive character;

- contradictions in argumentation;

- contradictions in information: inaccurate, insufficient, unsound, disputable etc.;

- contradictions between arguments and conclusions, the premise and the conclusion; cause and effect etc.

Accordingly, the results obtained show that creative situations can provide the necessary conditions for the development of creative and heuristic abilities of learners:

- to generate ideas, use analogy;

- to deconstruct contradictions, problems;

- to develop logical, critical, creative imagination;

- to evolve flexibility of thinking;

- $\quad$ to develop creative thinking;

- to provide transference of knowledge, skills and habits.

\section{CONCLUSION}

Thus, innovative pedagogical management as a very important factor in the formation of students' creativity in the education system should quite reasonably be in the focus of attention of scientists and practitioners in various fields. It is important to take into account that for the development of professional creative potential, it is necessary to have the possibility of self-realization in such areas as self-awareness, reflection, self-determination, self-organization. Only under these conditions, we can train competitive specialists who can successfully function in the modern world with its avalanche-like information flow. And as the 
obtained results show creative situations can provide the realization of these aims.

\section{AUTHORS' CONTRIBUTIONS}

Nadzeya Nizhneva-Ksenofontova developed the methods of the research and wrote the manuscript; Natallia Nizhneva created the concept of the research and contributed to revising and editing.

\section{REFERENCES}

[1] H. S. Lichtman. What is Telehresence? // Telehresence Options, Spring, 2011 - URL. Access mode: http://telepresenceoptions.com/magazine/subs cribe.php. Date of access: 08.07.2013.

[2] T. I. Lubart, R. J. Sternberg. Defying the crowd: cultivating creativity in a culture of conformity publisher, 1995. Access mode: http://www.creativityatwork.com/articlesCont ent/whatis.htm. Date of access: 25.09. 2011.

[3] R. May. The courage to create. 1994. Access mode:

http://www.allgraphicdesign.com/phpBB2/vie wtopic.php? $\mathrm{f}=6 \& \mathrm{p}=15740$. Date of access: 25.09. 2011.

[4] M.D. Mumford. Where Have We Been Where Are We Going? Taking Stock in Creativity Research/ "Creativity Research Journal". 2003, Volume 15, Issue 2, pp. 107-120.

[5] L. D. Parker, P. A Ritson Revisiting Fayol anticipating contemporary management. British Journal of Management, Sep vol 16 no 3. 2005, pp.175-194.

[6] K.B. Everard, G.Morris. Effective School management.- London: PaulChapman. 1985.

[7] K.B. Everard, G.Morris. Effective School management.- London: PaulChapman. 1985, p.10.

[8] E. V. Tereshchenkova, Yu. V. Golchenko. Innovative pedagogical management: the essence, features and conditions for implementation in an educational institution / / Scientific and methodological electronic journal "Concept". - 2013. - Volume 3. - C. 3206-3210. - URL: http://ekoncept.ru/2013/53647.htm.

[9] S. F. Taziev. Innovative management in education: A textbook. - Elabuga, 2009, p. 25.
[10] E. V. Tereshchenkova, Yu. V. Golchenko. Innovative pedagogical management: the essence, features and conditions for implementation in an educational institution / / Scientific and methodological electronic journal "Concept". - 2013. - Volume 3. C. 3206-3210. - URL: http://ekoncept.ru/2013/53647.htm

[11] S. F. Taziev. Innovative management in education: A textbook. Elabuga, 2009, 159 p.

[12] L. A. Zatsepilov. The development of creativity of students in the higher military educational institution in the study of the humanities: dissertation ... candidate of pedagogical sciences: 13.00.08 / Zatsepilova Larisa Aleksandrovna.- Ulyanovsk, 2011, 221 p.

[13] O. V. Bondarenko Modern innovative technologies in education / "RONO" Issue 16 (September 2012) Access mode: https://sites.google.com/a/shko.la/ejrono_1/vy puski-zurnala/vypusk-16-sentabr2012/innovacii-poiski-iissledovania/sovremennye-innovacionnyetehnologii-v-obrazovanii. Accessed date: 28. 02. 2019.

[14] Yu. S. Gaiduchenko. Educational process and innovative management in modern pedagogy / Psychopedagogy in law enforcement agencies. 2009. No. 1 (36). - pp. 58-61.

[15] G. S. Altshuller. Search for new ideas: from insight to technology: (Theory and practice of solving inventive problems) / G. S. Altshuller., B. L. Zlotin, A.V. Zusman, V. I. Filatov. Chisinau: Carta of moldoveneasca, 1989, 382 p.

[16] M. M. Zinovkina. Multilevel continuous creative education and school. A Handbook for teachers. M.: Priority-MV, 2006, 48 p.

[17] V.Utemov, M.Zinovkina, P Gorev. Creative pedagogy. Training manual. - Yurayt. 2019, $212 \mathrm{c}$.

[18] Yu. S. Gaiduchenko. Educational process and innovative management in modern pedagogy / Psychopedagogy in law enforcement agencies. 2009. No. 1 (36). pp. 58-61.

[19] M. Czerwonka, M. Karwowski. The order matters: asking about creative activity calibrates creative self-concept "Creativity 
Research Journal". 2018, Volume 30, Issue 2. pp. 179-186.

[20] H. Long, An empirical review of research methodologies and methods in creativity studies (2003-2012), “Creativity Research Journal”. 2014, Volume 26, Issue 4. pp. 427438.

[21] S. Skalicky, A. Scott, D. S. Crossley, McNamara, K. Muldner. Identifying creativity during problem solving using linguistic features. "Creativity Research Journal". - 2017, Volume 29, Issue 4. pp. 343-353.

[22] S. T. Hunter, K. E. Bedell, M.D. Mumford, Climate for creativity: a quantitative review "Creativity Research Journal". - 2007, Volume 19, Issue 1. pp. 69-90.

[23] S. Mann, R. Cadman. Does being bored make us more creative? "Creativity Research Journal”. - 2014, Volume 26, Issue 2. pp. 165173.

[24] T. Kettler, N.Kristen, K.N.Lamb, A Willerson, D. R. Mullet. Teachers' perceptions of creativity in the classroom, "Creativity Research Journal”. - 2018, Volume 30, Issue 2. pp. 164-171.

[25] M. A. Runco. The standard definition of creativity, "Creativity Research Journal". 2012, Volume 24, Issue 1. pp. 92-96.

[26] R. J. Sternberg. The nature of creativity, "Creativity Research Journal". 2006, Volume 18, Issue 1. pp. 87-98.

[27] L. Naiman. What is creativity? 2010. www.creativityatwork.com Date of access: 25 September, 2011.

[28] M. D. Mumford. Where have we been, where are we going? Taking stock in creativity research, "Creativity Research Journal". 2003. Volume15. p.110.

[29] R. May. The courage to create. 1994. http://www.allgraphicdesign.com/phpBB2/vie wtopic.php?f=6\&p=157407 Date of access: 25 September, 2011.

[30] T. I. Lubart, R. J. Sternberg. Defying the crowd: cultivating creativity in a culture of conformity publisher. 1995. http://www.creativityatwork.com/articlesCont ent/whatis.htm Date of access: 25 September, 2011.
[31] J. F. Feldhusen, B. E. Goh. Assessing and accessing creativity: an integrative review of theory, research, and development. "Creativity Research Journal", 1995.8 (3): 231. 17p.

[32] E. P. Kelly. When sparks fly: igniting creativity in groups. The Academy of Management Executive. - 2000. 14(1). p. 157.

[33] D. K. Smith, D. B. Paradice, S. M. Smith. Prepare your mind for creativity. Association for Computing Machinery. Communications of the ACM. 2000. 43(7). p. 110.

[34] J. Thomas. Nine barriers to thinking creatively, Women in Business. 1999. 51(1). p.14. 